\title{
Nuevos patrones de identidad y memoria en la Europa transmoderna
}

\author{
Christiane Stallaert ${ }^{1}$ \\ University of Antwerp / Catholic University of Leuven, Bélgica \\ E-mail: christiane.stallaert@artesis.be
}




\section{Resumen}

En el presente texto proponemos nuevas herramientas conceptuales para interpretar el paisaje humano de la Europa del siglo XXI. Argumentamos que la Europa actual, caracterizada como transmoderna, se puede leer como un espacio heterotópico de la Modernidad, delimitada por dos fechas emblemáticas: 1492 y 1942. Si durante la Modernidad el patrón de identificación social se representaba metafóricamente por las raíces de un árbol, la metáfora identitaria de la Transmodernidad es el radicante (Bourriaud). Esta metáfora sugiere un cambio de enfoque para el análisis de procesos de memoria. En vez de memoria colectiva (Halbwachs), que sugiere una interpretación común y valores compartidos, proponemos la noción de memoria compilada (collected memory, Young). En una Europa transmoderna la memoria social se construye a partir de una compilación de memorias (nacionales, regionales y locales) y sus contra-memorias. Leer este nuevo paisaje de memoria supone descifrar, mediante traducciones diacrónicas y sincrónicas, la sintaxis radicante por la que transitan las identidades transmodernas.

Palabras clave: Europa. Transmodernidad. Identidad colectiva. Memoria social.

\section{Abstract}

In this paper, we propose new conceptual tools for interpreting the human landscape of XXI century Europe. We argue that today's Europe, characterized as trans-modern, can be read as a heterotopic space of Modernity, bounded by two emblematic dates: 1492 and 1942. If during Modernity the social identification pattern is represented metaphorically by the roots of a tree, the metaphor of trans-modern identity is the radicant (Bourriaud). This metaphor suggests a shift in focus for the analysis of memory processes. Instead of collective memory (Halbwachs), suggesting a common understanding and shared values, we propose the notion of collected memory (Young). In trans-modern Europe social memory is constructed from a compilation of memories (national, regional and local) and their counter-memories. To read this new landscape of memory means deciphering -through diachronic and synchronic translations- the radicant syntax connecting transiting transmodern identities.

Keywords: Europe. Trans-modernity. Collective identity. Social memory. 


\section{Introducción}

Dara analizar los procesos de identificación colectiva en la Europa del siglo XXI necesitamos nuevas herramientas conceptuales que permitan dar cuenta de la profunda transformación demográfica que este continente está experimentando desde la segunda mitad del siglo XX. Proponemos el concepto de transmodernidad como herramienta conceptual para interpretar el paisaje humano de la Europa actual. Argumentamos que la Europa del siglo XXI se puede leer como un espacio heterotópico de la Modernidad, delimitada por dos fechas emblemáticas: 1492 y 1942. Ambos hitos históricos contribuyen a vertebrar la memoria social de la Europa transmoderna. Si durante la Modernidad el ideal del patrón de identificación social se representaba metafóricamente por las raíces de un árbol, la metáfora identitaria de la Transmodernidad puede ser el radicante (Bourriaud, 2009). Esta metáfora novedosa resulta interesante para el análisis de procesos de memoria en la nueva Europa del siglo XXI. Sugerimos sustituir el concepto de memoria colectiva (Halbwachs, 1925), que sugiere una interpretación común y valores compartidos, por la noción de memoria compilada (collected memory, Young, 1993). En una Europa transmoderna la memoria social se construye a partir de una compilación de memorias (nacionales, regionales y locales) y sus respectivas contramemorias que llenan los 'lugares de memoria' del paisaje europeo de significados heterogéneos, incompatibles y hasta conflictivos. Leer este paisaje supone descifrar, mediante traducciones diacrónicas y sincrónicas, la sintaxis radicante por la que transitan las identidades transmodernas. Nos apoyaremos en tres metáforas que expresan el vínculo entre la identidad y el lugar, a saber, las raíces, el rizoma y 
el radicante, para ejemplificar dicha transformación de una Europa moderna en transmoderna.

\section{Raíces}

El ideal de la identidad nacional moderna abarca un largo periodo de la historia europea cuyos hitos más señalados son las fechas emblemáticas de 1492 y 1942. La primera fecha se vincula con el inicio de la construcción de una nación homogénea en España mientras que la segunda marca el inicio del Holocausto y simboliza el momento histórico que llevaría posteriormente al cuestionamiento de este modelo nacional.

La metáfora más representativa de la identidad colectiva en la Europa Moderna son las raíces de un árbol. Las raíces se hunden en la tierra que alimenta el tronco y la copa con su savia. La salud del árbol requiere periódicamente una poda de las ramas enfermas e infectas. Blut und Boden - sangre y suelo- traducen metafóricamente esta concepción radical (derivado de raíces) de la identidad nacional y extirpar es la acción clave que garantiza la salud de la nación.

Extirpar y destruir fue la misión que se propuso la España moderna (los Reyes Católicos) de cara a las minorías etnorreligiosas (judíos y musulmanes) en suelo peninsular. A partir de 1492, año de la Toma de Granada y conquista del último reino musulmán en la Península Ibérica, la construcción de la nación española se caracteriza como un largo proceso de destierros, extirpaciones y amputaciones de miembros infectos. Sucesivamente serán expulsados los judíos (1492), los musulmanes (1502-1525) y los moriscos (1609), mientras que la totalidad de la población quedará sometida a un proceso de disciplinamiento y vigilancia, ejercido principalmente por la Inquisición, con el objetivo de homogenizar al cuerpo nacional. Este proceso lo hemos analizado en detalle en publicaciones anteriores (Stallaert, 1998; 2006).

En su diccionario etimológico de la lengua castellana, Corominas (1954, p. 433) relaciona el verbo extirpar (del latín exstirpare, desarraigar, arrancar) con el sustantivo estirpe, tomado del latín stirps, base de un árbol, pero también raza, familia, estirpe o linaje. En la Alemania 
de 1942, esta acción clave de la construcción nacional moderna se traduce por ausrotten, verbo que pertenece al léxico del Tercer Reich, como observó agudamente el judío alemán Victor Klemperer (2001, p. 256) .

Si bien estamos definiendo los contornos de la Europa Moderna a través de la relación traslatoria entre dos acciones extirpar y ausrotten, resulta interesante observar que el modelo identitario de la Europa moderna es un modelo reacio a la traducción. La traducción significa el diálogo entre culturas, un puente por el que se van trasvasando ideas, tradiciones o memorias. La identidad radical característica de la Europa Moderna, sin embargo, privilegia el monólogo de la nación consigo misma, en el intento de mantener (o recuperar) una supuesta pureza originaria, la pureza genética del Volkskörper, el cuerpo colectivo concebido como un organismo homogéneo de células genéticamente idénticas y autorreproductivas. La amputación de miembros indeseados o infectos en el proceso de construcción nacional (como la poda de las ramas podridas de un árbol) es la consecuencia más inmediata de este repliegue identitario, de la hostilidad a los puentes y trasvases culturales, de la incapacidad, en fin, de una auténtica comunicación inter- o transcultural, es decir, de traducción (Stallaert, 2006).

Tal identidad moderna representada metafóricamente por las raíces y el árbol - sangre y suelo -, se deja estudiar muy bien de acuerdo con un modelo epistemológico arbóreo (pensemos en el árbol de Porfirio). Es el modelo al que remiten las taxonomías antropológicas que clasifican jerárquicamente las diferentes razas o castas de acuerdo con su grado de pureza, partiendo ya sea del ideal cristianoviejo (1492), ya sea del ideal ario ( 1942). En los famosos cuadros de castas del imperio colonial español o en el organigrama de los presos de los campos de concentración nazi la realidad humana se clasifica de acuerdo a categorías cerradas, sin puentes ni trasvases, ordenadas según la lógica radical. El Holocausto conduce a la quiebra de este modelo. La realidad europea de la segunda mitad del siglo XX se caracteriza por intensos flujos de personas, de culturas y de información. Los nuevos paisajes políticos, sociales, culturales e identitarios presentan una sintaxis novedosa cuya lectura requiere de un nuevo marco interpretativo. 


\section{Rizoma}

Varios son los prefijos con los que se ha intentado colmar la necesidad de renovación conceptual creada a partir de la crisis de la Modernidad. Al margen de posibles alternativas tales como pos-, altero sur-modernidad, proponemos el prefijo trans para investigar los procesos identitarios en la Europa de hoy. El concepto de transmodernidad fue acuñado en 1989 por la filósofa española Rosa María Rodríguez Magda en su libro La sonrisa de Saturno. Hacia una teoría transmoderna. Independientemente de su primera puesta en circulación en España, el concepto surgió en los años 90 igualmente en América Latina (Enrique Dussel), en Bruselas (en un informe de la Comunidad Europea), así como en Nueva York en una exposición internacional de arquitectura (Rodriguez Magda, 2004). El caso es interesante porque nos muestra cómo la génesis del término de transmodernidad obedece a los propios mecanismos transmodernos y se aleja del modo monogenético y jerárquico característico de la identidad radical para adoptar rasgos rizomáticos y multicrónicos. Tal y como el concepto mismo de la transmodernidad, las identidades transmodernas obedecen a un modelo poligenético, caracterizado por brotaciones simultáneas horizontales sin centro ni jerarquía.

Si aplicamos este modelo a las identidades colectivas cabe representar el espacio europeo actual como una extensa superficie compuesta, por un lado, de desiertos -amplias zonas relativamente homogéneas donde predominan las identidades radicales, ya sea modernas (nacionales) o pre-modernas (locales)-y, por otro lado, de nodos: las grandes urbes con una población móvil y diaspórica donde, a partir del entrecruce de memorias sociales desterritorializadas, se fraguan las nuevas identidades cosmopolitas. A diferencia de la memoria nacional y local, orientada hacia el pasado en su búsqueda de mitos fundacionales, la memoria cosmopolita mira hacia el futuro e implica algún reconocimiento de la historia y las memorias del Otro (Levy e Sznaider, 2002). A diferencia de la identidad moderna, reacia a la traducción, ésta (la traducción) se ha convertido en el modo característico y constitutivo de la identidad transmoderna. 
Si las zonas desérticas del paisaje europeo se siguen aferrando por lo general a una identidad radical -el pueblo idéntico a su propia imagen y semejanza-, los nodos son los laboratorios del mestizaje, de la creolización. Si relacionamos este proceso con el sentido etimológico de criollo, a saber, persona nacida fuera del territorio étnico o ancestral, el criollo en la Europa actual es el inmigrante de las grandes ciudades. Históricamente hablando, la Modernidad europea a pesar de su ideal de nación homogénea fue un importante catalizador de los procesos de creolización a escala mundial, principalmente debido al imperialismo y colonialismo. El proyecto identitario de la Europa Moderna cuyo inicio hemos fijado simbólicamente en el contexto peninsular español de 1492, se centró en la expulsión de judíos y musulmanes. Paradójicamente, ambos 'otros' de la Europa Moderna protagonizan la renovación de los paradigmas identitarios en la Europa posmoderna. En su famoso ensayo, Georg Simmel definió al judío europeo como el prototipo del extraño o extranjero, el "que viene hoy y se queda mañana" -, y que "por naturaleza no es el dueño de la tierra" (Simmel, 2010)². El mismo rasgo lo comparte hoy el judío con la población musulmana que llegó a Europa después de la II Guerra Mundial como trabajadores invitados para quedarse, cambiando radicalmente el paisaje de las urbes europeas. Así, en los nodos creolizados del espacio europeo confluyen hoy las memorias y contra-memorias de Europa, mientras que los desiertos siguen siendo los depositarios de la memoria canónica (Assmann, 2010) nacional y local. Conviene observar, no obstante, que la población móvil y diaspórica en las urbes europeas cosmopolitas, a pesar de ser una población desterritorializada y por lo tanto geográficamente cortada de sus raíces identitarias, intenta recrear su identidad moderna (nacional) o premoderna (étnica /etnorreligisoa) manteniendo vivas ciertas prácticas sociales tradicionales como rituales y fiestas, lengua o creencias religiosas. El término de transmodernidad nos permite captar esta complejidad, ya que a diferencia de las alternativas post-, sur- o alter-, el prefijo trans- no rechaza la Modernidad, sino que parte de la misma aunque transformándola y trascendiéndola. En este sentido, la realidad transmoderna abarca identidades sociales modernas (nacionales), premodernas (étnicas) y posmodernas (híbridas o mestizas). 


\section{Radicante}

Ahora bien, ¿cómo definir, estudiar o representar la memoria social de una Europa transmoderna? ¿Qué puede significar, en una configuración social tan compleja como la Europa de hoy, la tensión entre memoria, el pasado presente, e historia, el pasado pasado (Nora, 1992)? ¿Cabe hablar de una memoria europea colectiva? Para formular una respuesta tentativa, recurrimos a la teoría estética del crítico de arte francés Nicolas Bourriaud (2009).

Hablando del arte en la era de la globalización, caracterizado por un proceso de creolización, Bourriaud disocia el territorio de origen o ancestral -en el que la identidad está arraigada- de lo que él llama un espacio radicante, es decir, un espacio que nace 'de una diáspora de signos implantados en un suelo circunstancial' (Bourriaud, 2009, p. 84-85). Lo que constituye la identidad del sujeto radicante no son las raíces en sí sino la trayectoria, la puesta en movimiento de las raíces, la organización del éxodo, que deja marcado el territorio con sus sucesivos arraigos (Bourriaud, 2009, p. 88).

Las ideas de Bourriaud se pueden trasladar al campo de los Estudios de Memoria y de las identidades, y nos invitan a repensar 'los cuadros sociales de la memoria' (Halbwachs, 1925). Efectivamente, está claro que la nueva realidad social de la Europa del siglo XXI, en cuanto a la creación de una memoria colectiva o social, es difícilmente compatible con la noción de lugar de memoria, que evoca lo estático y lo territorialmente arraigado. ¿Cómo aplicarle la noción de lugar como soporte de la memoria social al criollo o alóctono, el que se encuentra literalmente out-of-place (fuera de lugar). Históricamente, fue la búsqueda de una identidad radical la que forzó al Otro de la Modernidad europea a emprender el éxodo y a adoptar una identidad radicante. Hoy, en los albores del siglo XXI, el paisaje de la memoria europea se construye a través del reencuentro y diálogo de las memorias sociales europeas con sus distintas contra-memorias, las memorias heterotópicas que quedaron excluidas del canon nacional o local. Leer este paisaje supone dejarse llevar por la sintaxis radicante por la que transitan las memorias sociales y sus respectivas contra-memorias. A diferencia de la noción de memoria colectiva que sugiere una interpretación común 
y valores compartidos o consensuados, el paisaje europeo del siglo XXI se define mejor como un espacio de memorias sociales compiladas (collected memories, Young, 1993).

\section{Monumento a las víctimas del Holocausto}

Un buen ejemplo para ilustrar lo anterior es el Monumento a las Víctimas del Holocausto en Madrid. Aunque se trata de un lugar de memoria situado en España, es obvio que, de acuerdo con la lógica rizomática y radicante, podríamos iniciar nuestro itinerario en cualquier otro lugar del espacio europeo. En nuestro análisis, intentaremos interpretar la sintaxis que conecta este monumento con 1) el desierto del entorno (depositario de la memoria local y nacional) y 2) otros nodos del paisaje europeo (las urbes donde se fragua la memoria cosmopolita).

El Monumento a las Víctimas del Holocausto, inaugurado en 2007, se ubica en el Jardín de las Tres Culturas del parque Juan Carlos I, un parque creado en el emblemático año de 1992 en una zona de rehabilitación, en un nudo de autopistas en la periferia de Madrid. Su ubicación confiere al lugar de memoria que el Memorial pretende ser, todas las características de un no-lugar, marcado por la uniformidad, la falta de interacción y ausencia de vínculos sociales con el entorno (Augé, 1992). El Monumento es una escultura hecha de traviesas de madera de ferrocarril y exhibe una Estrella de David, símbolo de la comunidad judía, aunque la placa conmemorativa no sólo menciona a 'las víctimas judías' sino también 'españolas, gitanas y de otros colectivos, que fueron asesinados en los campos de exterminio' (Agencia Efe, 2007). Paradójicamente, la elección del tren como símbolo destaca la marginalidad del Monumento con respecto a la memoria del entorno. Efectivamente, el tren en representación de la ausrottung de los judíos europeos (1942) es ajeno a la historia y a la memoria de España, donde la extirpación de los judíos (1492) se realizó con medios inquisitoriales y por mar.

Otro elemento que destaca la falta de vínculo de este Monumento con la memoria social del entorno es su ubicación en el llamado Jardín de las Tres Culturas, un jardín con el que se pretende 'revalorizar y recuperar' el espíritu de las Tres Culturas como 'herencia de España' 
(Parque Juan Carlos, 2010). Si bien la referencia a las 'Tres Culturas' pertenece a la historia peninsular (el pasado pasado o el archivo de la memoria), obviamente no forma parte de la memoria social (el pasado presente o el canon). Como hemos observado anteriormente, el proceso de construcción nacional de España se caracterizó como una serie de amputaciones - podas - y no como un proceso integrador de minorías y es aquel proceso, el antagonismo identitario con musulmanes y judíos, el que quedó inscrito en la memoria social española (Stallaert, 1998).

Visto desde el desierto, el conjunto de Monumento y Jardín aparece como un no-lugar en el paisaje español ya que sus referentes remiten más bien a la contra-memoria que al canon de la memoria social española. Apela, pues, más bien a una memoria cosmopolita (integradora de las contra-memorias) característica de los nodos del paisaje europeo (las grandes urbes) que a la memoria local o nacional. Entender su significado como lugar de memoria supone leer este Monumento de acuerdo con su sintaxis específica como parte de la red de nodos del paisaje europeo.

Si aplicamos tal lectura, resulta interesante observar el mapa europeo de Memoriales del Holocausto y fijarse en la situación respectiva de España y Grecia (Memoriales del Holocausto) ${ }^{3}$. La comparación de ambos países en cuanto a la presencia de dichos Memoriales destaca la marginalidad española con respecto al Holocausto y la centralidad de Grecia. Se trata de dos posiciones muy distintas y distantes que, no obstante, están vinculadas entre si por la sintaxis radicante, ya que la abundante presencia de Memoriales del Holocausto en Grecia se deriva, precisamente, de su ausencia en España. Las comunidades judías de Grecia víctimas del nazismo, eran mayoritariamente sefarditas, descendientes de los expulsados de España en 1492. El Memorial de Tesalónica, erigido en memoria de los 54.000 judíos de la ciudad que murieron en el Holocausto, representa un candelabro de siete brazos y sugiere la forma de un árbol cuya copa simboliza a las víctimas. A diferencia del Memorial de Madrid, el de Tesalónica sí conecta plenamente con la memoria social del entorno ya que alude indirectamente al nuevo arraigo que habían encontrado en esta ciudad los sefardíes diaspóricos expulsados de la Península Ibérica en 1492, año fundacional de la modernidad europea. 
La memoria de los sefardíes nos lleva a su vez a Holanda, país que hizo de la tolerancia su seña de identidad nacional. Al igual que el Imperio Otomano, Holanda fue a partir de 1492 un refugio para los sefardíes, y en los siglos posteriores los Países Bajos se convirtieron en símbolo europeo de la libertad de conciencia y de la convivencia religiosa. La proverbial tolerancia holandesa no sólo abrió las puertas a los judíos sefardíes en el siglo XVI, sino que también durante la época nazi Holanda se convirtió en tierra de refugio de numerosos judíos europeos. La casa de Anne Frank en Amsterdam es uno de los museos del Holocausto más visitados y ocupa un lugar importante en la memoria social holandesa. Se produjo gran conmoción social en torno a la muerte del árbol del patio de la casa (Support Anne Frank Tree $)^{4}$. La desaparición del árbol se puede leer metafóricamente como la desaparición de la comunidad judía de Amsterdam, ciudad que durante siglos había sido un centro importante de la vida judía en Europa hasta su erradicación en 1942.

La sintaxis radicante nos conduce igualmente a Amberes (Bélgica). Esta ciudad vivió su Siglo de Oro gracias al refugio de judíos sefardíes y marranos procedentes de la Península Ibérica. A diferencia de Amsterdam, la presencia judía en Amberes se recuperó después de la Segunda Guerra Mundial como parte integral del paisaje urbano. Hoy, Amberes es la única ciudad europea donde se mantiene vivo el yiddish y la presencia significativa de hasidim (judíos ortodoxos) le ha valido a la ciudad el sobrenombre de 'Jerusalén de Occidente'. En las últimas décadas, en Amberes como en otras grandes ciudades de Europa, la población musulmana de origen inmigrante ha crecido de forma espectacular, hasta constituir una amplia mayoría en ciertas zonas urbanas. La situación en Oriente Medio y el avance del islamismo explican que la convivencia entre los diferentes grupos etnorreligiosos en Europa se ha ido tensando. Hoy, tanto en Bélgica como en otros países europeos, la integración de la población musulmana se mide por el respeto que muestra esta minoría de origen marroquí o turco por la memoria nacional del Holocausto. El ejercicio no resulta fácil, ya que en muchos casos se trata de dos memorias conflictivas. La difusión de mensajes antisemitas y negacionistas figura entre las alegaciones 
jurídicas contra un grupo de islamistas de Amberes que pretende instaurar la Sharia o ley islámica en Bélgica. Al mismo tiempo, la amplia difusión de Mi lucha en Turquía se cita como argumento contrario a la adhesión de este país a la Unión Europea.

A pesar del progresivo deterioro de la convivencia y el desencanto con la realidad multicultural, las autoridades de Amberes proyectan la ciudad como la Córdoba del Escalda, inspirándose en el modelo hispánico medieval de las Tres Culturas anterior a 1492. Y así la referencia a Córdoba nos lleva de regreso a España, donde iniciamos nuestro recorrido. En los últimos años, Córdoba como símbolo de la Europa pre-moderna ha venido a ocupar un lugar destacado en el discurso político sobre la convivencia entre culturas en la Europa post-moderna. Córdoba es un referente importante de la Alianza de Civilizaciones lanzada en 2004 por los entonces presidentes de España y de Turquía, Zapatero y Erdogan. Restaurar el espíritu de Córdoba significaría restaurar la convivencia o coexistencia entre las diferentes culturas y religiones que conviven en suelo europeo.

\section{A modo de conclusiones}

En el presente análisis hemos recurrido a tres metáforas, a saber, las raíces, el rizoma y el radicante, para reconstruir la trayectoria transcurrida por Europa desde 1492, inicio de la Modernidad, a la Transmodernidad.

La Europa transmoderna del siglo XXI se caracteriza por la textura compilada de su paisaje de memoria en el que 1492 y 1942 se presentan como dos poderosos ejes vertebradores, que, sin embargo, se traducen diferentemente de acuerdo con la memoria social de los diferentes actores. En tiempos de globalización, la memoria de Europa ha dejado de ser el patrimonio exclusivo de los europeos, es decir, de los de la tierra o autóctonos, sino que ha pasado a pertenecer también a los criollos, los que hunden sus raíces fuera del territorio europeo y que son los productos desechados de la Modernidad europea, herederos de los múltiples Otros de este continente.

En la Europa de hoy, caracterizada por la presencia de grandes contingentes de inmigrantes no europeos, confluyen y se entrechocan 
las memorias de Occidente con sus contramemorias. El gran desafío para la Europa del siglo XXI es la creación de una memoria cosmopolita.

\section{Notas:}

1 Profesora de Antropología en la Universidad Católica de Lovaina y de Estudios Hispánicos, Traducción y Comunicación Intercultural en la Universidad de Amberes (Bélgica). Ha sido profesora visitante en la École des Hautes Études en Sciences Sociales de París, en las Universidades de Santa Catarina (Brasil), Constanza (Alemania), Madrid, La Coruña y Tarragona. Es autora de varios libros, e.o.: Ni una gota de sangre impura. La España inquisitorial y la Alemania nazi cara a cara (Barcelona, 2006), Perpetuum Mobile: entre la balcanización y la aldea global (Barcelona, 2004), Etnogénesis y etnicidad en España. Una aproximación histórico-antropológica al casticismo (Barcelona, 1998), 'Hechos diferenciales' y convivencias interétnicas en España (Amsterdam/Atlanta, 1999).

2 Disponible em: < http://orgtheory.files.wordpress.com/2010/08/simmel01.pdf $>$.

3 Disponible em: <http://www.memorial-museums.net/WebObjects/ITF $>$.

4 Disponible em: <http://www.support-annefranktree.nl/>.

\section{Referencias}

AGENCIA EFE. 16 abr. 2007. Disponible en: < http://www.elmundo.es/ elmundo/2007/04/15/madrid/1 176634677.html>. Consultado: 10 oct. 2012.

ASSMANN, Aleida. Canon and Archive. In: ERLL Astrid; NÜNNING, Ansgar (Org.). A Companion to Cultural Memory Studies. Berlin/New York: De Gruyter, 2010. p. 97-107.

AUGÉ, Marc. Non-lieux: introduction à une anthropologie de la surmodernité. Paris: Seuil, 1992.

BOURRIAUD, Nicolas. Radicant. Pour une esthétique de la globalisation. París: Denoël, 2009.

COROMINAS, Juan. Diccionario crítico de la lengua castellana. Berna: Francke, 1954. v. II.

HALBWACHS, Maurice. Les cadres sociaux de la mémoire. Paris: Librairie Félix Alcan. Première édition, 1925. Edición digital disponible en: < http:// classiques.uqac.ca/classiques/Halbwachs_maurice/cadres_soc_memoire/ cadres_soc_memoire.html >.Consultado: 10 oct. 2012.

KLEMPERER, Victor. LTI-Apuntes de un filólogo. Barcelona: Minúscula, 2001.

LEVY, Daniel; SZNAIDER, Natan. Memory Unbound: The Holocaust and the Formation of Cosmopolitan Memory. European Journal of Social Theory, v. 5, n. 1, p. 87-106, 2002. 
MEMORIALES DEL HOLOCAUSTO. [2012]. Disponible en: < http://www. memorial-museums.net/WebObjects/ITF>. Consultado: 10 oct. 2012.

NORA, Pierre. Les lieux de mémoire. Paris: Gallimard, 1992.

PARQUE JUAN CARLOS. [2010]. Disponible en: < http://www.

parquejuancarlos.net/parquejuancarlosi/jardin.htm $>$. Consultado: 30 ago. 2010.

RODRIGUEZ MAGDA, Rosa María. La sonrisa de Saturno. Hacia una teoría transmoderna. Barcelona: Anthropos, 1989.

- Transmodernidad. Barcelona: Anthropos, 2004.

SIMMEL, Georg. 'The Stranger'. [2012]. Disponible en: < http://orgtheory. files.wordpress.com/2010/08/simmel01.pdf>. Consultado: 10 oct. 2012.

STALLAERT, Christiane. Etnogénesis y etnicidad en España: una aproximación histórico-antropológica al casticismo. Barcelona: Anthropos, 1998.

. Ni una gota de sangre impura: la España inquisitorial y la Alemania nazi cara a cara. Barcelona: Galaxia Gutenberg, 2006.

SUPPORT ANNE FRANK TREE. [2012]. Disponible en: < http://www. support-annefranktree.nl/>. Consultado: 10 oct. 2012.

YOUNG, James E. The Texture of Memory. Holocaust Memorials and Meaning. New Haven/London: Yale University Press, 1993.

Recebido em 12/10/2012

Aceito em 20/11/2012 